Word count $=7921$

\title{
Keeping the kids home: Increasing concern for others in times of crisis
}

\author{
Johannes Leder, Astrid Schütz, and Alexander Pastukhov \\ University of Bamberg
}

\begin{abstract}
Author Note
This research was funded by an intramural grant from the University of Bamberg (FNK 02069904). The funding source had no involvement in the study design, data collection, data analysis, interpretation of data, writing, or decision to submit. We thank Annette Malapally for help with the programming of the online study and Lea Stumpf for help with data collection.

The reported studies were preregistered and all data and materials are available online (https://osf.io/6e7bc/?view_only=3601702f784b4c92b13fac09a5a301eb).
\end{abstract}

Contact: Johannes Leder, johannes.leder@Uni-bamberg.de, Lehrstuhl für Persönlichkeitspsychologie und Psychologische Diagnostik Universität Bamberg Markusplatz 3 (Zi. M3/302), 96047 Bamberg, Germany, Tel: $0049(0) 951863-1817$

Contributions: All authors planned the study. The first author implemented the study and conducted the analyses together with the third author. The first author wrote the first draft of the paper. All authors revised and approved the final manuscript.

The manuscript is the accepted version of the paper to be published as part of the special issue "Understanding Others in Moments of Crisis" edited by Schneider, D., Burgmer, P., Erle T. and Ferguson, H in Social Psychology. Please cite as: Leder J., Schütz, A. and Pastukhov, A. (accepted). Keeping the kids home: Increasing concern for others in times of crisis. Social Psychology. Special Issue: Understanding Others in Moments of Crisis. https://doi.org/10.1027/1864-9335/a000463 


\begin{abstract}
During the COVID-19 pandemic social consequences in day-to-day decisions might not have been salient to the decider and thus egoistic. How can prosocial intentions be increased? In an experimental vignette study with $\mathrm{N}=206$, we compared the likelihood that parents send sick children to kindergarten after four interventions (general information about COVID-19, empathy, reflection of consequences via mental simulation, and control group). Independent of the intervention, empathic concern with individuals who were affected by COVID-19 and the salience of social consequences were high. The reported likelihood of sending a sick child to kindergarten was somewhat reduced in the control group and even more reduced in the reflection and empathy group, but not in the information group.
\end{abstract}

Keywords: COVID-19, prosocial intentions, empathy, crisis, mental simulation 


\section{Keeping the kids home: Increasing concern for others in times of crisis}

During the crisis of the COVID-19 pandemic, parents have had to decide whether to keep sick children at home, even if they had only mild cold symptoms. When making this decision, parents had to consider the cost of taking a sick day and the social benefit of preventing possible infections. Can the salience of the negative consequences of one's actions for the public or another individual affect parents' decisions and increase concern for others? In other words, does this result in a tendency to keep a child with mild symptoms at home?

Prosocial intentions are reflected in the willingness to engage in behavior that primarily benefits another person and includes behaviors such as helping, donations, or cooperation (Penner et al., 2004). Prosocial intentions and behaviors are shown to be a result of person and situation variables, such as the social value orientation of the individual or the interdependence of actors (Thielmann et al., 2020). Keeping sick children at home is an example of prosocial behavior as it increases the welfare of others by reducing the likelihood of making others sick.

To increase the likelihood of keeping sick children at home - a behavior that protects the public while incurring a personal cost_-parents need to consider the effects of their behavior on others. We propose that in such decisions prosocial intentions can be increased through empathy and through reflection of social consequences through mental simulation. In the current paper, we present an intervention study that tests the proposition that both empathy towards an individual and the reflection on social consequences through mental simulation increase the likelihood to keep even mildly sick children at home.

\section{Sending Sick Children to Kindergarten: Problem and Potential Remedies}

The private decision to send a sick child to kindergarten can have consequences for the parent, the child, and for others. Preventing infection is challenging in kindergarten settings with 
children under six years of age (Hashikawa et al., 2020) given the characteristics of COVID-19 (European Centre for Disease Prevention and Control, 2020) which can make people infectious even if they do not show symptoms.

Children aged 3-6 years cannot yet follow the rules of social distancing, and according to government regulations in Germany are not obliged to wear facemasks. At the same time, when infected with COVID-19 children often have only mild symptoms (Qiu et al., 2020). Still, kindergarten centers typically only deny attendance if there are severe symptoms (fever, severe cough, etc.). Thus, a parent's decision to keep a sick child at home is an important factor in reducing the risk for others and the spread of COVID-19.

\section{Ways to Increase Concern for Others}

The likelihood of sending children with mild symptoms to kindergarten may be reduced by sanctions, information, empathy, or reflection on social consequences through mental simulation. Sanctioning mechanisms, such as punishment (Fehr \& Gächter, 2002; Gürerk et al., 2006), interpersonal aggression, complaints to authority, or public shaming (Nelissen \& Mulder, 2013; Nelissen \& Zeelenberg, 2009) increase cooperation regarding the common good.

However, sanctions are often inefficient, as they are costly (Rockenbach \& Milinski, 2006) and do not work if detection is unlikely (Bornstein \& Weisel, 2010). For example, sanctioning parents who send infected children to daycare would have to be enforced by the kindergarten staff, which is difficult. For this reason, pathways have to be found to influence parents' intentions when making decisions by increasing the salience of costs for others in their personal—and yet fully social_ _ decision about sending their child to kindergarten.

Humans consider consequences for others in their decisions under risk. If humans are aware that a risk that has positive consequences for others, that decreases risk aversion (Leder \& 
Betsch, 2016) and negative consequences increase risk aversion (Pahlke et al., 2011; Trautmann \& Vieider, 2012). Furthermore, when uncertain about the possible negative impact of their decisions, people tend to be cautious to prevent harm for others - but only if these consequences are salient (Kappes et al., 2018). When deciding whether to keep a child home, consequences for others may not be salient - a feature that differs from typical laboratory experiments on risk taking. Thus, parents who do not consider negative consequences for others at this point may decide to send a child to daycare despite mild symptoms of disease.

One obvious way to render decisions more prosocial, that is, favoring options that are likely to increase the welfare of others, would be to provide information about social effects of a behavior. However, providing only information about the seriousness of the disease (Pfattheicher, Nockur, et al., 2020) or appealing to the decider's social responsibility (Favero \& Pedersen, 2020; Utych \& Fowler, 2020) did not alter intentions in previous research. A more promising path relies on appeals to empathy.

Empathy has been defined as the emotional response towards another person in need which is reflected in empathic concern (Batson et al., 1991). Empathic concern increases prosocial behavior in general (Eisenberg \& Miller, 1987), and specific prosocial behavior such as hand hygiene of medical professionals (Grant \& Hofmann, 2011; Sassenrath et al., 2016) and increases prosocial intentions specific to infectious disease such as social distancing, wearing a mask (Pfattheicher et al., 2020), and accepting vaccinations (Gagneur, 2020; Pfattheicher, Petersen, et al., 2020).

To experience empathic concern, cognitive empathy and taking another person's perspective are considered necessary. Accordingly, the instructions of experiments that test the effect of empathy for prosocial behavior often use perspective taking to manipulate empathic 
concern (e.g., "imagine how the person who is being interviewed feels about..." Batson et al., 1988) and contrast this intervention with a condition in which participants are told not to think about the other person (e.g., "Try to focus on the technical aspects of the broadcast." Batson et al., 1988). It is possible that emotional involvement on the basis of focusing on another individual's suffering and feeling with them is actually not necessary to foster prosocial tendencies. Instead, thoroughly considering consequences for others may be enough which could be achieved by mental simulation.

Mental simulation refers to thoroughly considering information and forming mental representations of different antecedents and their respective consequences. Mental simulation, such as imagined contact with others, has been shown to influence social behavior (Crisp et al., 2011), moral judgments (Byrne, 2017), and reduce prejudice (Hodson et al., 2009). When reading about others and forming a detailed mental representation on their state, a person considers several options and outcomes, and because a more abstract processing style increases concern for others (Woltin et al., 2011) such detailed information processing in mental simulation should also foster prosocial behavior.

When contrasting appeals to empathy with information about social consequences, previous research used short statements that pointed to the social consequences of behavior (Favero \& Pedersen, 2020; Utych \& Fowler, 2020) or mere information about the disease without clear social implications (Pfattheicher, Nockur, et al., 2020). Both types of information may be processed in a shallow fashion (De Jong \& Ferguson-Hessler, 1996) and probably for that reason did not change behavior. We suggest that the impact of information can be increased through mental simulation which should increase social concern even if there is no appeal to pity. Thus, to reflect on the social consequences of one's actions through mental simulation will 
increase salience of social consequences and the effects should be similar to the effects of empathic concern.

Both reflection on social consequences and empathy might increase the salience of consequences for others but they present different pathways towards prosocial behavior. Whereas empathy relates to individuals affected and is a specific emotional reaction (SchröderAbé \& Schütz, 2011), reflecting on social consequences is more abstract, requires deliberate information processing and does not focus on one specific individual but on the collective.

\section{Present Study}

In the present study, we compared three forms of communicating the risk of transmitting COVID-19 (general information about COVID-19, reflecting on social consequences through mental simulation, and the induction of empathy) regarding their effects on the probability of keeping a sick child home. The intervention was between subjects and the factors (severity of symptoms, availability of alternative childcare, and severity of expected social sanctions) were systematically varied within subjects to avoid ceiling and floor effects. Using an experimental study vignette study with parents, we tested the following hypotheses:

(1) General information about COVID-19 does not influence intentions.

(2) Induction of empathy decreases intentions to send children to kindergarten.

(3) Reflecting social consequences decreases intentions to send children to kindergarten.

(4) Induction of empathy and reflection have similar short-term effects on intentions. Investigating these hypotheses allows us to test two ways to increase prosocial intentions: a) understanding abstract social consequences and b) focusing on specific affected individuals. Furthermore, we assessed social value orientation (Murphy \& Ackermann, 2014), trait empathy (Spreng et al., 2009) and social desirability (Satow, 2012) as potential covariates. 
The study was conducted in line with the Declaration of Helsinki and the guidelines of the German Psychological Association. Participants provided informed consent before starting the study. There was no deception and the local ethics committee approved the study. We report how we determined our sample size, all data exclusions (if any), all manipulations, and all measures in the study (Simmons et al., 2012).

The preregistration, power analysis and materials are found here: https://osf.io/6e7bc/?view_only=3601702f784b4c92b13fac09a5a301eb.

\section{Method}

\section{Participants}

Parents $(\mathrm{N}=206,84 \%$ female; for detailed demographical information see Table $\mathrm{S} 1$ in the electronic supplements) completed vignettes (pre-treatment baseline, stage: pre), responded to personality questionnaires, received one of three interventions or a control treatment, and completed vignettes a second time (post-treatment, stage: post). The dependent variable was the reported likelihood to send a child to kindergarten under the circumstances described in the vignette. Finally, personal information how many children a participant had, how many currently attended kindergarten, availability of care when keeping children at home, employment status, family status, and attitude towards measures against COVID-19 spread were collected.

The sample size was based on a power analysis, setting both $\beta_{\text {cost }}=0$ and $\beta_{\text {sanctions }}=0$. We chose a conservative estimate (all effects at least 2SD from 0 ) and set Power $(1-\beta)=.8$. The simulation indicated that to find an effect between baseline and post-treatment in one group we would need $\mathrm{N}=50$ (for the code of the simulation see: https://osf.io/6e7bc/?view_only=3601702f784b4c92b13fac09a5a301eb). Thus, considering the four groups, the required sample size was set to $\mathrm{N}=200$. 
Participants were parents with children attending kindergarten and were recruited from our local participant's database ORSEE (Greiner, 2015), via university lists, and directly through childcare institutions that shared the link with parents. As a thank you, participants were eligible to participate in a raffle of three books or ten amazon gift certificates, $10 €$ each.

\section{Exclusion Criteria}

We had preregistered to exclude participants who: 1. provided the same responses across all vignettes. 2. have no children in kindergarten. 3. did not finish the survey. $\mathrm{N}=341$ participants responded to the survey. $\mathrm{N}=217$ completed all vignettes. No one provided the same response across all vignettes. $\mathrm{N}=206$ had at least one child.

We deviated from the preregistered exclusion criterion of having children in kindergarten as the item apparently led to misunderstandings. Some participants responded with values of zero and commented that children are in kindergarten but currently not attending, others stated 20 or 40, which clearly refers to the numbers in the kindergarten as a whole. Excluding participants who have children but responded with zero or with a number larger than the number of children in the respective household (e.g., 2 children but 20 in kindergarten), would have resulted in the exclusion of an additional $\mathrm{N}=17$ participants and reduction of the sample to $\mathrm{N}=189$. For this reason, we decided to exclude only participants who had no children.

\section{Design}

In the vignettes, three factors were varied, the symptoms of the child ( 5 levels), the difficulty of caring for the child at home (3 levels), and social sanctions (3 levels). Participants were randomly assigned to one of the following four groups: information only, information and reflecting social consequences through mental simulation, empathy induction, and a control group. 


\section{Materials}

\section{Vignettes}

For each vignette, three factors were varied (wording and levels see Table 1), the symptoms of the child (5 levels), the difficulty of caring for the child at home (3 levels), and social sanctions (3 levels). They were pseudo-randomized and from all 45 possible withinsubject combinations we sampled 15 combinations for each subject in order to reduce strain on participants.

\section{Table 1}

Vignettes Factor Levels.

\begin{tabular}{|c|c|c|}
\hline Factor & Level & Wording \\
\hline \multirow[t]{5}{*}{ Symptoms } & 1 & $\begin{array}{l}\text { Your child's nose is running a little today. Otherwise, it feels good. It doesn't } \\
\text { have a fever. }\end{array}$ \\
\hline & 2 & $\begin{array}{l}\text { Your child's nose is running a little today. Every now and then it has to cough } \\
\text { lightly. Otherwise, it feels good. It doesn't have a fever. }\end{array}$ \\
\hline & 3 & $\begin{array}{l}\text { Your child is coughing today and complaining of a sore throat. It feels a little } \\
\text { weak. It doesn't have a fever. }\end{array}$ \\
\hline & 4 & $\begin{array}{l}\text { Your child is coughing today and complaining of a sore throat. It feels a little } \\
\text { weak. Your child's temperature is slightly increased, but they do not have a } \\
\text { fever. }\end{array}$ \\
\hline & 5 & $\begin{array}{l}\text { Your child is having a persistent, strong cough today. It feels pretty weak. They } \\
\text { also have a fever and aches and pains in their muscles or limbs. }\end{array}$ \\
\hline \multirow{3}{*}{$\begin{array}{l}\text { Care } \\
\text { availability }\end{array}$} & 1 & At least one legal guardian is at home all day today. \\
\hline & 2 & A friend or relative could look after the child today. \\
\hline & 3 & $\begin{array}{l}\text { You (and, if applicable, the other legal guardian) both have to work outside the } \\
\text { home today. }\end{array}$ \\
\hline \multirow[t]{3}{*}{ Social pressure } & 1 & $\begin{array}{l}\text { If your child goes to kindergarten despite these symptoms, other parents and the } \\
\text { kindergarten management will understand. }\end{array}$ \\
\hline & 2 & $\begin{array}{l}\text { If your child goes to kindergarten despite these symptoms, other parents will } \\
\text { get upset and address you critically. }\end{array}$ \\
\hline & 3 & $\begin{array}{l}\text { If your child goes to kindergarten despite these symptoms, other parents will } \\
\text { get annoyed and respond critically to you and also inform the kindergarten } \\
\text { management. }\end{array}$ \\
\hline
\end{tabular}


All symptom levels were included and difficulty of caring for the child and social sanctions were randomly selected for each participant. In each vignette symptoms of the child were described first, then care availability, and finally social sanctions. Here is an example: "Your child is coughing today and complaining of a sore throat. The child feels a little weak. The child doesn't have a fever (symptoms level 3). A friend or relative is able to look after the child today (available care level 2). If your child goes to kindergarten despite these symptoms, other parents will get upset and criticize you (social sanctions level 2)."

The vignettes were presented in random order, but each participant received the same set of vignettes at $\mathrm{t} 1$ and $\mathrm{t} 2$. This combination of a between and within-subjects design allowed for comparing responses of each participant before and after the intervention while keeping the context constant and allowed to compare the effect of all factor levels between participants.

\section{Dependent Variable}

In each vignette, we asked, "how likely is it that you will send your child?" on a scale of 0-100.

\section{Intervention}

In all groups, participants read texts that were similar in length. The text was presented on the screen and continuation of the survey was possible after a minimum of 60-seconds.

In the information-only group, participants received an informative text from the Robert Koch Institute (Germany's national public health institute) detailing facts about the coronavirus, its transmission, and protection against it. Pfattheicher et al. (2020) also used that same text.

In the information plus reflecting on social consequences group, participants received the same text as in the information group and were instructed to mentally simulate how many people 
could be affected if their child would go to kindergarten despite being infected with the COVID19 virus. To guide the mental simulation, three questions had to be answered: What is your estimate, how many children can be infected by one sick child? What is your estimate, how many adults can in turn be infected by these children? Overall, how many people can one infected child infect?

In the empathy group, participants read a text, in which a woman with a rare immune disease (membranoproliferative glomerulonephritis Type III) reported to have suffered from a coronavirus infection and detailed how serious her condition had been (comatose and in the intensive care unit), which is the same text as used by Pfattheicher et al. (2020).

In the control group, participants read a Wikipedia entry, which described the history and purpose of kindergartens.

\section{Manipulation check}

After the intervention, participants responded to items measuring state empathy and the salience of the social consequences of sending a sick child to kindergarten. As in previous research (Batson et al., 1997; Pfattheicher, Nockur, et al., 2020), as a measure of state empathy participants were asked to indicate their agreement with the following three statements on a fivepoint scale (1-5) concerning people who are sick with COVID-19: "I have compassion", "The situation moves me", and "The situation touches me" (Cronbach's $\alpha=.83$ ). To measure salience of social consequences participants responded to the question "What do you estimate, how serious could the consequences of your behavior be for the collective?" on a five point scale that ranged from very low (1) to very high (5). 


\title{
Personality measures
}

Social value orientation was measured with the six primary items from the SVO slider measure (Murphy et al., 2011). We assessed social desirability using the respective German scale by Satow (2012) with seven items (Cronbach's $\alpha=.67$ ), and trait empathy with the Toronto Empathy Questionnaire (Spreng et al., 2009) containing ten items, translated into German by the authors (Cronbach's $\alpha=.74)$.

\section{Additional measures}

Participants were also asked to indicate their perceived vulnerability as well as the vulnerability of others on a five-point scale that ranged from very low (1) to very high (5): "What do you think, how dangerous is the Corona-Virus to you / other people?". We then measured the attitudes regarding COVID-19 protective measures with three items: a) assessing how informed the participant is about the rules regarding sick children in daycare, b) compliance with hygiene rules, c) evaluation of the current measures against COVID-19 as sufficient, sufficient, or too severe.

\author{
All materials can be found on OSF \\ (https://osf.io/6e7bc/?view_only=3601702f784b4c92b13fac09a5a301eb).
}

\section{Statistical analysis}

We used two statistical models. A simple model included only effects of experimental manipulations, whereas an extended one also included personality variables (trait empathy, social-value orientation, social desirability). The additional terms specific to the extended model are shown in red. 
The outcome variable is a probability of sending the child to daycare with the actual response range from 1 to 101 . We scaled it using the following formula

$$
R_{i}=0.0005+0.999 \cdot \frac{\text { Response }_{i}-1}{100}
$$

We used smaller range from 0.0005 to 0.9995 as extreme values of 0 and 1 translate into negative and positive infinity under the logit link.

$$
\begin{aligned}
& R_{i} \sim \operatorname{Beta}\left(\mu_{i}, 1 / \sigma\left[S_{i}\right]\right) \\
& \operatorname{logit}\left(\mu_{i}\right)=\alpha_{p_{i}}+\text { Personality }_{i}+\text { Stage }_{i} \cdot \beta_{T}\left[T_{i}\right]+\text { Stage }_{i} \cdot \beta_{S T}\left[T_{i}\right] \cdot \theta_{S}\left[S_{i}\right]+\text { Vignette }_{i} \\
& \text { Personality }_{i}=\beta_{E} \cdot E_{i}+\beta_{S V O} \cdot S V O_{i}+\beta_{S D} \cdot S D_{i} \\
& \text { Vignette }_{i}=\beta_{S} \cdot \theta_{S}\left[S_{i}\right]+\beta_{P} \cdot \theta_{P}\left[P_{i}\right]+\beta_{C} \cdot \theta_{C}\left[C_{i}\right]+\beta_{S C} \cdot \theta_{S}\left[S_{i}\right] \cdot \theta_{C}\left[C_{i}\right]+\beta_{S P} \cdot \theta_{S}\left[S_{i}\right] \cdot \theta_{P}\left[P_{i}\right] \\
& \sigma \sim \text { Exponential }(1) \\
& \alpha_{p_{i}} \sim \operatorname{Normal}\left(\alpha, \sigma_{\alpha}\right) \\
& \alpha \sim \operatorname{Normal}(0,0.5) \\
& \sigma_{\alpha} \sim \text { Exponential }(1) \\
& \beta_{E}, \beta_{S V O}, \beta_{S D} \sim \operatorname{Normal}(0,1) \\
& \beta_{T}[i], \beta_{S T}\left[T_{i}\right] \sim \operatorname{Normal}(0,0.1) \\
& \beta_{S}, \beta_{P}, \beta_{C}, \beta_{S C}, \beta_{S P} \sim \operatorname{Normal}(0,1) \\
& \theta_{S}[\mathrm{i}]=\sum_{j=0}^{i-1} \delta_{S}[j] \\
& \delta_{S} \sim \operatorname{Dirichlet}(2) \\
& \theta_{P, C}[1]=0, \theta_{P, C}[2]=\operatorname{Beta}(0.5,4), \theta_{P, C}[3]=1
\end{aligned}
$$

Subscript $i$ and $[i]$ refer to the index of the data point and subscript $p_{i}$ to the index of a participant. $S_{i}, P_{i}, C_{i}$, and $T_{i}$ are correspondingly the levels of symptoms severity (1 to 5), social pressure (1 to 3 ), care availability (1 to 3 ), and condition index, respectively.

To model the scaled outcome variable, we use reparametrized beta distribution with mean and precision parameters. As higher values of precision mean a tighter distribution, we reparametrized it as $1 / \sigma$, so that smaller values of $\sigma$ mean higher precision. Then, we use $\sigma \sim$ Exponential(1) as prior because it biases $\sigma$ towards zero and, therefore, higher precision. We allowed for a different precision parameter for each symptom level due to great variability of 
responses with distribution of responses changing from bimodal for level 1 to unimodal for levels 3-5.

Both models are multilevel, with participant-specific intercept $\left(\alpha_{p_{i}}\right)$ drawn from a distribution defined by a sample mean and standard deviation ( $\alpha$ and $\left.\sigma_{\alpha}\right)$.

Both models included vignette-specific factors Symptoms severity $\left(S\right.$ and $\left.\beta_{S}\right)$, social Pressure $\left(P\right.$ and beta $\left._{P}\right)$, and Care availability $\left(C\right.$ and $\left.\beta_{C}\right)$, two-way interactions between symptoms severity and care availability $\left(\beta_{S C}\right)$, and symptoms severity and social pressure $\left(\beta_{S P}\right)$, an interaction between stage (Stage $e_{i}$ encoded as 0 for pre-treatment, 1 for post-treatment) and treatment $\left(\beta_{T}\left[T_{i}\right]\right.$, where $T_{i}$ is 1 for control, 2 for empathy, 3 for information, and 4 for reflection), and a three-way interaction between experimental stage, treatment, and symptoms $\left(\beta_{S T}\right)$. The extended model also included effects of trait empathy $\left(E\right.$ and $\left.\beta_{E}\right)$, social-value orientation (SVO and $\beta_{S V O}$ ), and social desirability $\left(S D\right.$ and $\left.\beta_{S D}\right)$.

We treated symptoms severity, social pressure and care availability as categorical predictors because we expected that individual categories will not be evenly distributed between the extremes, which was confirmed by the model (see Figure 1). We modeled symptoms severity as a categorical predictor with the effect of the maximal level (5) encoded as $\beta_{S}$ and lower symptoms levels as ordered cumulative proportion of that effect. The symptoms of level $\mathrm{S}=1$ correspond to baseline $(0)$, level $\mathrm{S}=2$ to $\delta_{1}^{S}$, level $\mathrm{S}=3$ to $\delta_{1}^{S}+\delta_{2}^{S}$, level $\mathrm{S}=4$ to $\delta_{1}^{S}+\delta_{2}^{S}+\delta_{3}^{S}$, and level $S=5$ to $\delta_{1}^{S}+\delta_{2}^{S}+\delta_{3}^{S}+\delta_{4}^{S}=\sum_{j=0}^{S-1} \delta_{j}^{S}$. Note that $\sum_{j=0}^{(S=5)-1} \delta_{j}^{S}=1$ by definition. Similar logic was applied to social pressure and care availability predictors. However, both only had three levels. Given that we assign strength of 0 to the first (lowest) one and strength of 1 to 
the third (highest) one, we only need to fit the proportional strength of level two. We used beta distribution as a prior.

\section{Figure 1.}

Estimated Strength of Intermediate Levels of Categorical Variables Relative to Extremes ( 0 and 1).

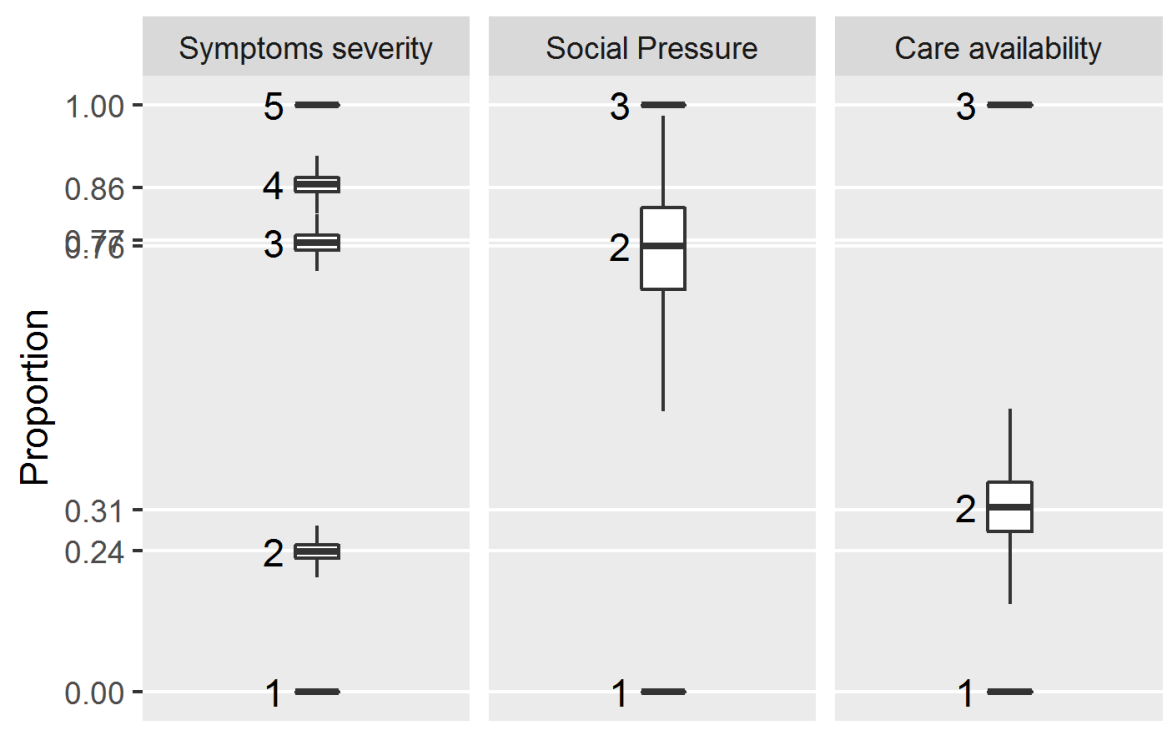

Note. Box plots depict posterior distribution of estimated level strength, except for fix levels of 0 and 1 for, correspondingly, smallest and largest levels.

As the two models produced very similar posterior distributions, we report them for the extended model. We characterized individual terms using the samples from the posterior distribution. All $\beta$ terms, except for the intercept, have units of log-odds that we converted to odds via exponential transformation. We reported means and $89 \%$ credible intervals of posterior distributions. The latter, also referred to as compatibility interval, is a range that contains $89 \%$ of the probability mass based on values from the sampled posterior distribution. 


\section{Results}

The means and standard deviation of all variables (aggregated responses to the vignettes for the pre and post measure respectively and their difference score on the individual level) and their bivariate correlations are depicted in Table 2. The distribution of SVO, empathy and social desirability are shown in the electronic supplement (Figure S1- Figure S3, correlations with the dependent variable for each intervention group are shown in Figure S6). 


\section{Table 2}

Means, Standard Deviations, and Correlations with Confidence Intervals for Measured Variables

\begin{tabular}{|c|c|c|c|c|c|c|c|c|c|}
\hline $\begin{array}{l}\text { Variable } \\
\text { 1. State empathy }\end{array}$ & $\begin{array}{c}M \\
4.34\end{array}$ & $\begin{array}{l}S D \\
0.78\end{array}$ & 1 & 2 & 3 & 4 & 5 & 6 & 7 \\
\hline 2. Salience Social cost & 4.54 & 0.78 & $\begin{array}{c}.29 * * \\
{[.16, .41]}\end{array}$ & & & & & & \\
\hline 3. Social desirability & 3.05 & 0.72 & $\begin{array}{c}.04 \\
{[-.10, .18]}\end{array}$ & $\begin{array}{c}-.02 \\
{[-.16, .12]}\end{array}$ & & & & & \\
\hline 5.Trait empathy & 4.08 & 0.43 & $\begin{array}{c}.41 * * \\
{[.29, .52]}\end{array}$ & $\begin{array}{c}.23 * * \\
{[.09, .35]}\end{array}$ & $\begin{array}{c}.03 \\
{[-.10, .17]}\end{array}$ & $\begin{array}{c}.18^{*} \\
{[.04, .31]}\end{array}$ & & & \\
\hline 6. Pre-intervention & 28.94 & 17.65 & $\begin{array}{c}-.18 * \\
{[-.31,-.04]}\end{array}$ & $\begin{array}{c}-.30 * * \\
{[-.42,-.17]}\end{array}$ & $\begin{array}{c}-.00 \\
{[-.14, .13]}\end{array}$ & $\begin{array}{c}.09 \\
{[-.04, .23]}\end{array}$ & $\begin{array}{c}-.15^{*} \\
{[-.28,-.01]}\end{array}$ & & \\
\hline 8. Change of intention & 3.59 & 9.10 & $\begin{array}{c}.03 \\
{[-.10, .17]}\end{array}$ & $\begin{array}{c}.02 \\
{[-.12, .16]}\end{array}$ & $\begin{array}{c}-.04 \\
{[-.17, .10]}\end{array}$ & $\begin{array}{c}.10 \\
{[-.04, .23]}\end{array}$ & $\begin{array}{c}.12 \\
{[-.02, .25]}\end{array}$ & $\begin{array}{c}.14^{*} \\
{[.00, .27]}\end{array}$ & $\begin{array}{c}-.36 * * \\
{[-.47,-.23]}\end{array}$ \\
\hline
\end{tabular}

Note. $M$ and $S D$ are used to represent mean and standard deviation, respectively. Values in square brackets indicate the $95 \%$ confidence interval for each correlation. ${ }^{*}$ indicates $p<.05$. ${ }^{* *}$ indicates $p<.01$. 


\section{Manipulation Check}

State empathy was higher in the empathy group than in the other three groups, but the effect was not significant. Salience of social cost was lowest in the reflection group than in the other three groups, but the effect was not significant (see Table 3, the effects are similar when carrying out an ordinal regression with a cumulative link function for state empathy see Table $\mathrm{S} 2$, in the ordinal regression with a cumulative link function the salience of social cost the was significantly lower in the reflection than control group see Table S3, both in the electronic supplements; density distributions are shown in Figure S4 and Figure S5 in the electronic supplements).

Table 3

Manipulation Check for State Empathy and Perceived Social Cost.

\begin{tabular}{lcccccc}
\hline & \multicolumn{6}{c}{ Dependent Variable } \\
\cline { 2 - 7 } & \multicolumn{3}{c}{ State Empathy } & \multicolumn{4}{c}{ Salience Social Cost } \\
\hline Predictors & $B$ & $95 \% C I$ & $p$ & $B$ & $95 \% C I$ & $p$ \\
(Intercept) & 4.27 & {$[4.07,4.48]$} & $<0.001$ & 4.65 & {$[4.45,4.86]$} & $<0.001$ \\
Intervention [information] & 0.01 & {$[-0.29,0.31]$} & 0.932 & -0.12 & {$[-0.42,0.18]$} & 0.417 \\
Intervention [reflection] & -0.02 & {$[-0.32,0.29]$} & 0.918 & -0.24 & {$[-0.54,0.06]$} & 0.122 \\
Intervention [empathy] & 0.26 & {$[-0.03,0.56]$} & 0.078 & -0.12 & {$[-0.41,0.18]$} & 0.430 \\
Observations & \multicolumn{3}{c}{206} & & \multicolumn{5}{c}{$0.012 /-0.003$} \\
$\mathrm{R}^{2} / \mathrm{R}^{2}$ adjusted & \multicolumn{3}{c}{$0.023 / 0.008$} & & & \\
\hline
\end{tabular}

\section{Test of Hypotheses}

The results and model predictions for the intermediate social pressure are presented in Figure 2, similar plots for the other two levels of social pressure can be found in the online repository. 


\section{Figure 2}

Distribution of Participants' Responses and Group-level Model Predictions for Level 2 of Social Pressure.
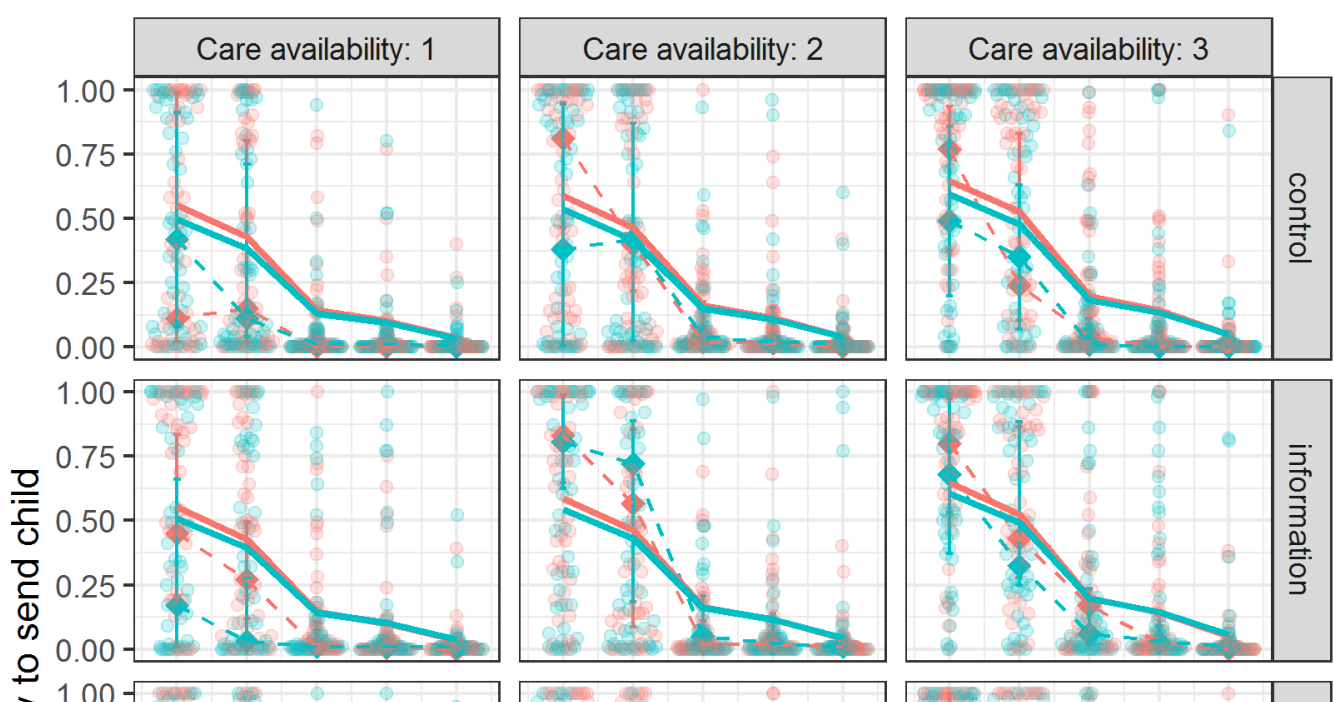

Stage
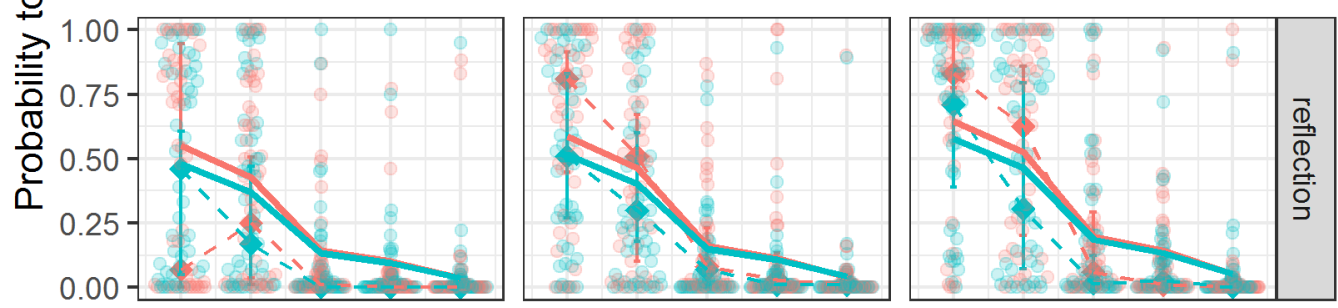

$\rightarrow$ pre
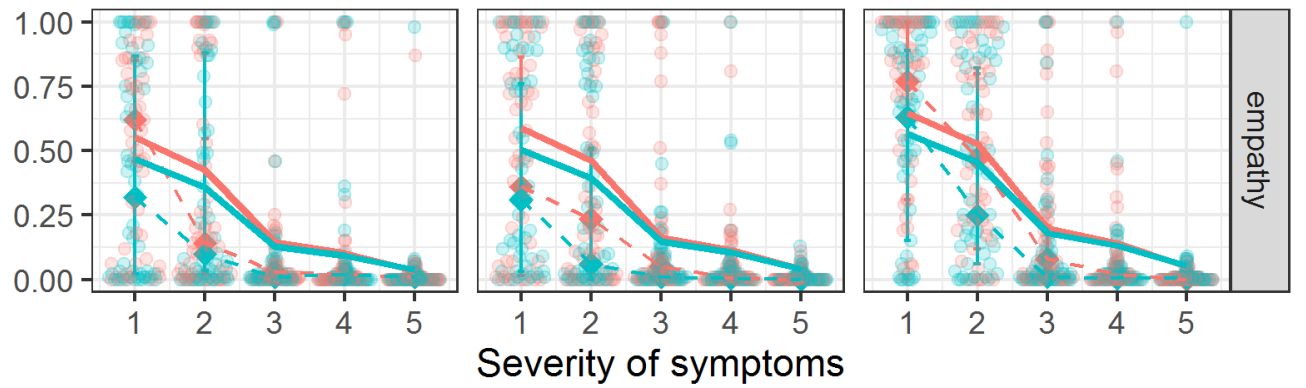

Notes. Semi-transparent circles denote responses of individual participants, diamonds and dashed lines - group-level mean, error bars - group-level 25\% - 75\% quantiles, solid lines group-level model predictions.

As expected, higher severity of symptoms of the child lead to strongly reduced probability of sending them to kindergarten: $\beta_{\text {symptoms }}=0.03,[0.025,0.034]$, odds for change of 
symptoms from minimal (1) to maximal (5), mean and 89\% credible interval. Similarly, difficulty in obtaining an alternative care increased the likelihood of sending child $\left(\beta_{\text {care }}=1.48\right.$, $[1.4,1.6]$, odds for change of care availability from maximal (1) to minimal (3)), whereas increased social pressed reduced it $\left(\beta_{\text {pressure }}=0.77,[0.7,0.85]\right.$, odds for change of social pressure from minimal (1) to maximal (3)).

We observed an overall effect of stage, i.e., change in responses to the same vignettes following an intervention. Specifically, a probability of sending a child to kindergarten was significantly reduced at $\mathrm{t} 2$ for the control group: $\beta_{\text {control }}=0.81[0.7,0.91]$ (in units of odds, mean and $89 \%$ credible interval). The probability was reduced even further in the empathy and reflection groups. The effect was somewhat stronger than in the control group with difference in odds being $\beta_{\text {empathy- }} \beta_{\text {control }}=-0.09[-0.22,0.03]$ (difference in odds, mean and $89 \%$ credible interval) and $\beta_{\text {reflection- }} \beta_{\text {control }}=-0.06[-0.19,0.08]$. The difference between these two interventions was negligible: $\beta_{\text {empathy- }} \beta_{\text {reflection }}=-0.04[-0.17,0.1]$. By contrast, information was even less effective than the control group: $\left.\beta_{\text {information }}-\beta_{\text {control }}=0.04[-0.11,0.19]\right)$.

As for interaction effects, we found a positive effect for the three-way interaction between the stage, the intervention, and the severity of the symptoms (odds for all slope coefficients were above 1.0). Note, however, that this interaction is not directly interpretable as its primary role is to account for the floor effect for symptoms levels 3-5 that make all responses identical irrespective of the stage or treatment. We observed no significant interaction between either symptoms and care availability $\left(\beta_{\mathrm{SC}}=1.03[0.74,1.5]\right.$, odds, mean and $89 \%$ credible interval) or symptoms and social pressure $\left(\beta_{\mathrm{SP}}=1.24[0.78,1.65]\right)$.

With respect to personality, we found that higher trait empathy was associated with reduced probability of sending sick children to a kindergarten $\left(\beta_{\text {empathy }}=0.85[0.79,0.92]\right.$, in 
units of odds, mean and $89 \%$ credible interval $)$, whereas neither social desirability $\left(\beta_{\mathrm{sd}}=0.99\right.$ $[0.91,1.07])$ or social value orientation $\left(\beta_{\mathrm{sd}}=1.04[0.97,1.13]\right)$ had no effect.

\section{Discussion}

We investigated how different interventions (information, empathy, and reflection of social consequences via mental simulation) influence parents' decisions to send a sick child to kindergarten. In all experimental groups, participants empathized with people who were sick with COVID-19 and perceived the social cost of sending sick children to kindergarten as being high. Social sanctions and availability of alternative care had a strong positive effect on the decision to keep children at home. However, the availability of care had more impact than social pressure. For all groups, including the control group but more so in the empathy and the mental simulation group, the likelihood of sending children to daycare was lower at the second stage (post-intervention measure), although the effect was stronger in the empathy and reflection group and weaker in the information group.

Our findings show that brief interventions, as used in our study, may have only small effects on prosocial intentions. In this specific case, a relevant factor may have been the fact that people had already adjusted their behavior during the pandemic and that they had experienced events that had already triggered empathy or social concern. We also found that personality, in our case trait empathy, had an additional effect on behavioral intentions, which was similar to the effect of our interventions.

\section{Empathy and Understanding Others as Processes Influencing the Salience of Consequences for Others in Decision-making.}

We observed a high degree of empathy and salience of social consequences in all groups, including the control group. This finding differs from previous results (Pfattheicher, Nockur, et 
al., 2020) even though we had used the same matierials. However, that study had been conducted at the onset of the pandemic and our study one year later. Our findings regarding levels of empathy are similar to the results of another study carried out later in the pandemic (Favero \& Pedersen, 2020). Thus, it seems possible that people have experienced personal threats during the pandemic or have seen the suffering of people close to them, and this may have increased empathic concern for others as well as salience of social consequences. In line with this reasoning, the fact that the intervention in the present study showed only small effects may be explained as a result of the fact that empathic concern and salience regarding social consequences were quite high among our participants. The finding is in line with recent survey research (Alonso-Ferres et al., 2020; Serrano-Montilla et al., 2021). Importantly, despite the lack of a significant differences in reported state empathy between intervention groups, the empathy group still responded in a more prosocial fashion than the control and the information group.

We observed that reflecting on social consequences through mental simulation has a similar effect on reducing the likelihood of sending sick children to kindergarten as empathy does. Perspective taking is considered to be one facet of empathy as it induces a focus on the other. Importantly, this processes may evoke feelings associated with the other and induce empathy (Shamay-Tsoory, 2011). The important differences between empathy and perspective taking, is that the former reflects an emotional response, whereas the latter, a rational one (Gilin et al., 2012). Reflecting on social consequences may involve perspective taking to some degree. Therefore, it is possible that in this case people not only reflect on the social consequences but also experience higher empathic concern. However, we did not find a higher level of state empathy in the reflection group compared to the control or information group. The reason for this could be that the reflection of social consequences did not focus on a specific individual but 
a large number of people and empathy is likely to not occur in such instances (Fetherstonhaug et al., 1997; Slovic, 2007).

Particularly in light of the lack of increased empathy, our findings suggests that reflecting social consequences induce an alternative way to prosocial behavior, which does not appeal to feelings but to understanding. First, our findings add to previous evidence which shows that mere information usually does not change behavior (Favero \& Pedersen, 2020; Pfattheicher, Nockur, et al., 2020; Utych \& Fowler, 2020); however, we found that guided reflection of a situation and the consideration of consequences can. Second, our findings underline the role of understanding as recent evidence shows that understanding the course of exponential growth during a pandemic (Lammers et al., 2020), or being educated about specific benefits, such as herd immunity (Griffith et al., 2020; Hakim et al., 2019; Logan et al., 2018) are important factors that influence prosocial behavior.

Trait empathy is positively correlated with prosocial behavior across multiple economic games (Thielmann et al., 2020). We found that this also holds for every-day social decisions. Furthermore, we found that trait empathy might cause the positive effect of social value orientation (SVO) as the relationship between sending children to kindergarten and SVO became zero, when controlling for trait empathy. This finding is similar to the observation that trait empathy explains gender differences in prosocial behavior (Kamas \& Preston, 2020). We assume that trait empathy influenced the decision by altering participants' utility function and making consequences for others more important (Kirman \& Teschl, 2010).

We found that empathy, both state and trait, were positively associated with the salience of social consequences and a lower likelihood to send sick children to kindergarten. On the one hand, this contradicts the assumption that empathic concern reduces one's focus on the collective 
(Batson et al., 1995, 1999) because of its focus on one individual (Batson et al., 2007), and specific helping behavior (Dovidio et al., 1990). On the other hand, our results are consistent with the idea that empathy can foster prosocial behavior for the collective, if the interests of the person in need and the collective are aligned or at least not in conflict (e.g., Grant \& Hofmann, 2011; Pfattheicher, Nockur, et al., 2020; Sassenrath et al., 2016).

\section{Limitations}

We used a control condition in which participants also read a text, herby holding everything constant across experimental groups and only manipulating the independent variable (salience of others via empathy or via reflection). This is different from previous research which used control groups in which no information was provided (Pfattheicher, Nockur, et al., 2020; Pfattheicher, Petersen, et al., 2020) and similar to the use of a control group with a placebo. Thus, in previous research experimental and control groups differed a) regarding treatment and b) whether a text was read or not. We wanted to rule out this confound, as the effect of reading something vs. not reading could influence subsequent decisions. However, it is unclear to what degree the content of the text read in our control group influenced the subsequent decisions. Our control text was about the purpose and history of kindergartens. We chose this text as it was related to the study topic. However, it is possible, that it directed attention towards the importance of kindergarten attendance for child development and, therefore, made participants more cautious in sending a sick child, in order not to compromise attendance of others. In addition, the reflection group also received three questions to guide the mental simulation. Although this differentiates this condition from the rest, these were necessary as reflection group was also the only one that required entering precise numerical values. We opted not to use neutral questions in other groups as it could distract the participants from their main task. 
Whereas prior work observed significant effects of the intervention, our work suggests a more cautious interpretation. First, our observed effects are small, which is in line with previous research. However, prior work used statistical methods that are problematic because ordinal oneitem responses were treated as interval scales and sample size was high, which resulted in $\mathrm{p}$ values that were very small, for example $\mathrm{p}<.001$ (e.g. experiment 4 Pfattheicher, Nockur, et al., 2020). The problem of using tests without paying attention to assumptions regarding their distribution assumptions has been recently addressed by Liddell and Kruschke (2018) — a criticism which must be considered by social psychologists to ensure replicability of results. In fact, the fields' current ignorance regarding this issue can inflate the alpha error and deflate pvalues. We overcame this caveat by using a hierarchical Bayesian model with ordinal predictor variables to account for non-linearity of the relationship between predictor and criterion and a beta distribution to account for the proportional measure (e.g., 50\% sending probability) of the criterion.

Our data was collected online. Thus, we were unable to control for distractions that could have reduced effect sizes. However, the responses to the mental simulation task show that (at least in that group) participants paid close attention when adding up the adults and children affected. As participants had been randomly assigned to groups, there is no reason to believe that attention was lower in the other groups.

Parents are a special group: they have limited time and are thus difficult to recruit. This was especially true during the COVID-19 pandemic. The sample size was calculated to result in enough power to test within group change. However, power was too low for group comparisons, which resulted in effects being less clear. Participants had self-selected and were prosocial individuals as indicated by the distribution of SVO scores, a fact that is typical in voluntary 
participants (Marcus \& Schütz, 2005). Furthermore, parents who were critical of the current measures against COVID-19 may have been less likely to participate as the study was advertised as a study on health-related questions in the current situation (although COVID-19 was not mentioned). The degree of agreement to the current measures within our sample reflects this tendency. Whereas the public's responses to a survey during the period of data collection (April 2021) show that $48 \%$ agreed with the official measures, $24 \%$ wanted stronger measures, and 24\% wanted fewer (ARD Deutschlandtrend Umfrage, statista.com). We found 50\% agreeing, $34 \%$ wanting stronger measures and $15 \%$ wanting fewer measures. Finally, most respondents were women, which could have influenced the overall prosocial tendencies, as women are typically more prosocial than men (Kamas \& Preston, 2020). Hence, our findings apply to women and generalizability to men has yet to be shown. However, as women in most families are responsible for childcare in Germany (BMFSF, 2020), our findings still have practical value.

Finally, the present study measured intentions and not behavior. Although, intentions are good predictors of behavior (Sheeran, 2002), the relationship is moderated by control over the behavior in question (Ajzen, 1991). For this reason, even if intentions are prosocial the unavailability of alternative care for a mildly sick child will determine the decision and override (good) intentions.

\section{Conclusion}

We found that salience of consequences for others can be increased via two pathways: a) reflecting on social consequences through mental simulation and b) the induction of empathy. Furthermore, we found that trait empathy was related to prosocial intentions independent of our intervention. Finally, our results suggest that interventions may be less effective when implemented later, as opposed to earlier in the course of a crisis, because over the course of that 
crisis participants or their close relations may have been personally affected and thus participants may better understand how their actions can impact others.

\section{Open Practices}

All materials including the analysis scripts, (translated) questionnaire files, and the data sets are available online at https://osf.io/6e7bc/?view_only=3601702f784b4c92b13fac09a5a301eb. All analyses have either been preregistered or marked as exploratory. We stated all deviations from the preregistration.

\section{Contributions}

- All authors planned the study. The first author implemented the study and conducted the analyses together with the second author. The first author wrote the first draft of the paper. All authors revised and approved the final manuscript. 


\section{References}

Ajzen, I. (1991). The theory of planned behavior. Orgnizational Behavior and Human Decision Processes, 50, 179-211. https://doi.org/10.1016/0749-5978(91)90020-T

Alonso-Ferres, M., Navarro-Carrillo, G., Garrido-Macías, M., Moreno-Bella, E., \& ValorSegura, I. (2020). Connecting perceived economic threat and prosocial tendencies: The explanatory role of empathic concern. PLOS ONE, 15(5), 1-25. https://doi.org/10.1371/journal.pone.0232608

ARD. (2021). Sind aus Ihrer Sicht die geltenden Corona-Maßnahmen in Deutschland alles in allem angemessen, gehen sie zu weit oder gehen sie nicht weit genug? [Graph]. Statista Das Statistik-Portal. https://e.statista.com/statistik/daten/studie/1233852/umfrage/umfragezu-corona-massnahmen-deutschlandtrend/

Batson, C. D., Ahmad, N., Yin, J., Bedell, S. J., Johnson, J. W., Templin, C. M., \& Whiteside, A. (1999). Two threats to the common good: Self-interested egoism and empathy-induced altruism. Personality and Social Psychology Bulletin, 25(1), 3-16.

Batson, C. D., Batson, J. G., Slingsby, J. K., Harrel, K. L., Peekna, H. M., \& Todd, R. M. (1991). Empathic joy and the empathy-altruism hypothesis. Journal of Personality and Social Psychology, 61, 413-427.

Batson, C. D., Batson, J. G., Todd, R. M., Brummett, B. H., Shaw, L. L., \& Aldeguer, C. M. R. (1995). Empathy and the collective good: Caring for one of the others in a social dilemma. Journal of Personality and Social Psychology, 68(4), 619-631. http://10.0.4.13/00223514.68.4.619

Batson, C. D., Dyck, J. L., Brandt, J. R., Batson, J. G., Powell, A. L., McMaster, M. R., \& Griffitt, C. (1988). Five studies testing two new egoistic alternatives to the empathy- 
altruism hypothesis. Journal of Personality and Social Psychology, 55(1), 52-77. http://10.0.4.13/0022-3514.55.1.52

Batson, C. D., Eklund, J. H., Chermok, V. L., Hoyt, J. L., \& Ortiz, B. G. (2007). An additional antecedent of empathic concern: Valuing the welfare of the person in need. Journal of Personality and Social Psychology, 93(1), 65-74. http://10.0.4.13/0022-3514.93.1.65

Batson, C. D., Sager, K., Garst, E., Kang, M., Rubchinsky, K., \& Dawson, K. (1997). Is empathy-induced helping due to self - other merging? Journal of Personality and Social Psychology, 73(3), 495-509. http://10.0.4.13/0022-3514.73.3.495

BMFSF. (2020). Who takes care of children, household and the elderly? A dossier on the societal dimension of a private question. bmfsfj.de

Bornstein, G., \& Weisel, O. (2010). Punishment, cooperation, and cheater detection in "Noisy" social exchange. Games, 1(1), 18-33. https://doi.org/10.3390/g1010018

Dovidio, J. F., Allen, J. L., \& Schroeder, D. A. (1990). Specificity of Empathy-Induced Helping: Evidence for Altruistic Motivation. Journal of Personality and Social Psychology, 59(2), 249-260. https://doi.org/10.1037/0022-3514.59.2.249

Favero, N., \& Pedersen, M. J. (2020). How to encourage "Togetherness by Keeping Apart” amid COVID-19? The ineffectiveness of prosocial and empathy appeals. Journal of Behavioral Public Administration, 3(2), 1-18. https://doi.org/10.30636/jbpa.32.167

Fetherstonhaug, D., Slovic, P., Johnson, S. M., \& Friedrich, J. (1997). Insensitivity to the value of human life: A study of psychophysical numbing. Journal of Risk and Uncertainty, 14(3), $282-300$.

Gagneur, A. (2020). Motivational interviewing: A powerful tool to address vaccine hesitancy. Canada Communicable Disease Report, 46(04), 93-97. 
https://doi.org/10.14745/ccdr.v46i04a06

Gilin, D., Maddux, W. W., Carpenter, J., \& Galinsky, A. D. (2012). When to use your head and when to use your heart: The differential value of perspective-taking versus empathy in competitive interactions. Personality and Social Psychology Bulletin, 39(1), 3-16.

Grant, A. M., \& Hofmann, D. A. (2011). It's not all about me: Motivating hand hygiene among health care professionals by focusing on patients. Psychological Science, 22(12), 14941499. https://doi.org/10.1177/0956797611419172

Greiner, B. (2015). Subject pool recruitment procedures: Organizing experiments with ORSEE. Journal of the Economic Science Association, 1(1), 114-125. https://doi.org/10.1007/s40881-015-0004-4

Griffith, B. C., Ulrich, A. K., Becker, A. B., Nederhoff, D., Koch, B., Awan, F. A., \& Basta, N. E. (2020). Does education about local vaccination rates and the importance of herd immunity change US parents' concern about measles? Vaccine, 38(50), 8040-8048. https://doi.org/10.1016/j.vaccine.2020.09.076

Hakim, H., Provencher, T., Chambers, C. T., Driedger, S. M., Dube, E., Gavaruzzi, T., Giguere, A. M. C., Ivers, N. M., MacDonald, S., Paquette, J. S., Wilson, K., Reinharz, D., \& Witteman, H. O. (2019). Interventions to help people understand community immunity: A systematic review. Vaccine, 37(2), 235-247. https://doi.org/10.1016/j.vaccine.2018.11.016

Hodson, G., Choma, B. L., \& Costello, K. (2009). Experiencing Alien-Nation: Effects of a simulation intervention on attitudes toward homosexuals. Journal of Experimental Social Psychology, 45(4), 974-978. https://doi.org/10.1016/j.jesp.2009.02.010

Kamas, L., \& Preston, A. (2020). Empathy, gender, and prosocial behavior. Journal of Behavioral and Experimental Economics, 92, 101654. 
https://doi.org/10.1016/j.socec.2020.101654

Kappes, A., Nussberger, A. M., Faber, N. S., Kahane, G., Savulescu, J., \& Crockett, M. J. (2018). Uncertainty about the impact of social decisions increases prosocial behaviour. Nature Human Behaviour, 2(8), 573-580. https://doi.org/10.1038/s41562-018-0372-x Kirman, A., \& Teschl, M. (2010). Selfish or selfless? The role of empathy in economics. Philosophical Transactions of the Royal Society Biological Sciences, 365, 303-317.

Lammers, J., Crusius, J., \& Gast, A. (2020). Correcting misperceptions of exponential coronavirus growth increases support for social distancing. Proceedings of the National Academy of Sciences of the United States of America, 117(28), 16264-16266.

https://doi.org/10.1073/pnas.2006048117

Logan, J., Nederhoff, D., Koch, B., Griffith, B., Wolfson, J., Awan, F. A., \& Basta, N. E. (2018). 'What have you HEARD about the HERD?' Does education about local influenza vaccination coverage and herd immunity affect willingness to vaccinate? Vaccine, 36(28), 4118-4125. https://doi.org/10.1016/j.vaccine.2018.05.037

Marcus, B., \& Schütz, A. (2005). Who are the people reluctant to participate in research? Personality correlates of four different types of noniesponse as inferred from self- And observer ratings. Journal of Personality, 73(4), 959-984. https://doi.org/10.1111/j.14676494.2005.00335.x

Murphy, R. O., \& Ackermann, K. A. (2014). Social Value Orientation: Theoretical and measurement issues in the study of social preferences. Personality and Social Psychology Review, 18(1), 13-41. https://doi.org/10.1177/1088868313501745

Murphy, R. O., Ackermann, K. A., \& Handgraaf, M. J. J. (2011). Measuring social value orientation. Judgment and Decision Making, 6(8), 771-781. 
http://journal.sjdm.org/11/m25/m25.html

Penner, L. A., Dovidio, J. F., Piliavin, J. A., \& Schroeder, D. A. (2004). Prosocial behavior: Multilevel perspectives. Annual Review of Psychology, 56(1), 365-392. https://doi.org/10.1146/annurev.psych.56.091103.070141

Pfattheicher, S., Nockur, L., Böhm, R., Sassenrath, C., \& Petersen, M. B. (2020). The Emotional Path to Action: Empathy Promotes Physical Distancing and Wearing of Face Masks During the COVID-19 Pandemic. Psychological Science, 31(11), 1363-1373. https://doi.org/10.1177/0956797620964422

Pfattheicher, S., Petersen, M. B., \& Böhm, R. (2020). Information about herd immunity and empathy promote COVID-19 vaccination intentions. (Preprint), January. https://doi.org/10.31234/osf.io/wzu6k

Rockenbach, B., \& Milinski, M. (2006). The efficient interaction of indirect reciprocity and costly punishment. Nature, 444(7120), 718-723. https://doi.org/10.1038/nature05229

Sassenrath, C., Diefenbacher, S., Siegel, A., \& Keller, J. (2016). A person-oriented approach to hand hygiene behaviour: Emotional empathy fosters hand hygiene practice. Psychology and Health, 31(2), 205-227. https://doi.org/10.1080/08870446.2015.1088945

Satow, L. (2012). Skala zur Erfassung von Testverfälschung durch positive Selbstdarstellung und sozialerwünschte Antworttendenzen (SEA). Skalendokumentation und Normen sowie Fragebogen mit Instruktion [PSYNDEX Tests-Nr. 9006446]. Leibniz-Zentrum Für Psychologische Information Und Dokumentation (ZPID)(Hrsg.), Elektronisches Testarchiv. Trier: ZPID.

Serrano-Montilla, C., Alonso-Ferres, M., Navarro-Carrillo, G., Lozano, L. M., \& Valor-Segura, I. (2021). Assessment of the effects of health and financial threat on prosocial and antisocial 
responses during the COVID-19 pandemic: The mediating role of empathic concern. Personality and Individual Differences, 178(March). https://doi.org/10.1016/j.paid.2021.110855

Shamay-Tsoory, S. G. (2011). The neural bases for empathy. Neuroscientist, 17(1), 18-24. https://doi.org/10.1177/1073858410379268

Sheeran, P. (2002). Intention-behavior relations: A conceptual and empirical review. European Review of Social Psychology, 12(1), 1-36. https://doi.org/10.1080/14792772143000003

Simmons, J. P., Nelson, L. D., \& Simonsohn, U. (2012). A 21 word solution. Dialogue: The Official Newsletter of the Society for Personality and Social Psychology, 26(2), 4-12.

Slovic, P. (2007). "If I look at the mass I will never act": Psychic numbing and genocide. Judgment and Decision Making, 2(2), 79-95. http://journal.sjdm.org/7303a/jdm7303a.htm

Spreng, R. N., McKinnon, M. C., Mar, R. A., \& Levine, B. (2009). The Toronto Empathy Questionnaire: Scale development and initial validation of a factor-analytic solution to multiple empathy measures. Journal of Personality Assessment, 91(1), 62-71. https://doi.org/10.1080/00223890802484381

Thielmann, I., Spadaro, G., \& Balliet, D. (2020). Personality and prosocial behavior: A theoretical framework and meta-analysis. Psychological Bulletin, 146(1), 30-90. https://doi.org/10.1037/bul0000217

Utych, S. M., \& Fowler, L. (2020). Age-based messaging strategies for communication about COVID-19. Journal of Behavioral Public Administration, 3(1), 1-14. https://doi.org/10.30636/jbpa.31.151

Woltin, K. A., Corneille, O., Yzerbyt, V. Y., \& Förster, J. (2011). Narrowing down to open up for other people's concerns: Empathic concern can be enhanced by inducing detailed 
processing. Journal of Experimental Social Psychology, 47(2), 418-424. https://doi.org/10.1016/j.jesp.2010.11.006 